\title{
Cardiac resynchronization therapy: a meta-analysis of randomized controlled trials
}

\author{
George Wells PhD, Ratika Parkash MD MSc, Jeffrey S. Healey MD MSc, Mario Talajic MD, \\ J. Malcolm Arnold MD, Shannon Sullivan MSc, Joan Peterson BA, Elizabeth Yetisir MSc, \\ Patricia Theoret-Patrick BScRN, Marilynn Luce BScRN, Anthony S.L. Tang MD
}

\begin{abstract}
Background: Studies of cardiac resynchronization therapy in addition to an implantable cardioverter defibrillator in patients with mild to moderate congestive heart failure had not been shown to reduce mortality until the recent RAFT trial (Resynchronization/ Defibrillation for Ambulatory Heart Failure Trial). We performed a meta-analysis including the RAFT trial to determine the effect of cardiac resynchronization therapy with or without an implantable defibrillator on mortality.
\end{abstract}

Methods: We searched electronic databases and other sources for reports of randomized trials using a parallel or crossover design. We included studies involving patients with heart failure receiving optimal medical therapy that compared cardiac resynchronization therapy with optimal medical therapy alone, or cardiac resynchronization therapy plus an implantable defibrillator with a standard implantable defibrillator. The primary outcome was mortality. The optimum information size was considered to assess the minimum amount of information required in the literature to reach reliable conclusions about cardiac resynchronization therapy.
Results: Of 3071 reports identified, 12 studies ( $n=7538$ ) were included in our meta-analysis. Compared with optimal medical therapy alone, cardiac resynchronization therapy plus optimal medical therapy significantly reduced mortality (relative risk [RR] $0.73,95 \%$ confidence interval $[\mathrm{Cl}]$ 0.62-0.85). Compared with an implantable defibrillator alone, cardiac resynchronization therapy plus an implantable defibrillator significantly reduced mortality (RR $0.83,95 \% \mathrm{Cl} 0.72-0.96$ ). This last finding remained significant among patients with New York Heart Association (NYHA) class I or II disease (RR $0.80,95 \% \mathrm{Cl} 0.67-0.96$ ) but not among those with class III or IV disease (RR 0.84, 95\% Cl 0.69-1.07). Analysis of the optimum information size showed that the sequential monitoring boundary was crossed, which suggests no need for further clinical trials.

Interpretation: The cumulative evidence is now conclusive that the addition of cardiac resynchronization to optimal medical therapy or defibrillator therapy significantly reduces mortality among patients with heart failure.

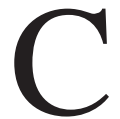
ongestive heart failure is currently reaching epidemic proportions in Canada, with 500000 Canadians affected and 50000 new patients identified each year. ${ }^{1}$ It accounts for more than 100000 hospital admissions per year and has a one-year mortality ranging from $15 \%$ to $50 \%$, depending on the severity of heart failure. ${ }^{2}$ By 2050, the number of patients with heart failure is projected to increase threefold. ${ }^{2}$

Advances in medical therapies have resulted in substantial reductions in mortality associated with congestive heart failure..$^{3-7}$ The use of de vices has recently become an important adjuvant therapy. ${ }^{8}$ Cardiac resynchronization therapy in volves pacing from both the right and left ventricles simultaneously to improve myocardial efficiency (see radiographs in Appendix 1, at www .cmaj.ca/cgi/content/full/cmaj.101685/DC1). Car- diac resynchronization therapy has been shown to reduce morbidity and, when compared with medical therapy alone, to reduce mortality. ${ }^{9-13}$ Until recently, it was not shown to reduce mortality among patients who also received an implantable cardioverter defibrillator. Among patients receiving optimal medical therapy, the Resynchronization/Defibrillation for Ambulatory Heart Failure Trial (RAFT) showed the superiority of cardiac resynchronization therapy in addition to an implantable defibrillator over a standard implantable defibrillator in reducing mortality and the combined outcome of death from any cause or hospital admission related to heart failure. ${ }^{14}$

We performed a meta-analysis to further assess the effect on mortality of cardiac resynchronization therapy with and without an im-
Competing interests: See end of article for competing interests.

Disclaimer: George Wells is a biostatistical consultant for $C M A J$ and was not involved in the editorial decision-making process for this article.

This article has been peer reviewed.

Correspondence to: George Wells, gawells@ottawaheart.ca

CMAJ 2011. DOI:10.1503 /cmaj.101685 
plantable defibrillator among patients with mildly symptomatic and advanced heart failure.

\section{Methods}

We used the PICO (population, intervention, comparison and outcome) approach to develop the research question for our systematic review. The population of interest included patients with mildly symptomatic or advanced heart failure, with a QRS interval of more than $120 \mathrm{~ms}$. The intervention of interest was cardiac resynchronization therapy with or without an implantable cardioverter defibrillator in patients receiving optimal medical therapy. Comparisons between the following interventions were made: cardiac resynchronization therapy versus optimal medical therapy alone; and cardiac resynchronization therapy with an implantable defibrillator versus a standard implantable defibrillator. Optimal medical therapy was defined as evidence-based use of angiotensin-converting-enzyme (ACE) inhibitors or angiotensin II receptor blockers, $\beta$-blockers, spironolactone (if indicated) and diuretics at a stable dose for at least one month. The primary outcome was all-cause mortality. Only studies that provided mortality data were included.

\section{Literature search}

We searched the MEDLINE (1980 to Dec. 31, 2010), EMBASE (1980 to Dec. 31, 2010) and Cochrane Library (1980 to Dec. 31, 2010) databases for literature on cardiac resynchronization therapy and implantable defibrillator in patients with heart failure. We also searched various sources of grey literature as well as the US Food and Drug Administration website. Bibliographies of relevant systematic reviews were manually searched. Details of our search strategies are available in Appendix 2 (www.cmaj.ca/cgi /content/full/cmaj.101685/DC1).

Eligible studies were randomized controlled trials evaluating the effects of cardiac resynchronization therapy compared with control in adults with symptomatic heart failure or arrhythmia. Patients may also have been receiving medical therapy or have an implantable defibrillator.

\section{Data extraction}

Two of us (R.P. and J.H.) independently screened each citation for inclusion. Two re viewers (G.W. and R.P.) independently reviewed the full-text version of relevant articles and extracted the following data from the included studies: baseline characteristics of the study population, interventions and comparison groups, features of the study design, and the outcome of mortality. If necessary, discrepancies between the two reviewers were resolved by discussion involving a third independent reviewer (A.T.) to achieve consensus.

\section{Assessment of risk of bias}

The Cochrane Risk of Bias Tool was used to assess the risk of bias in the included studies. ${ }^{15}$ With respect to trials evaluating cardiac resynchronization therapy, random allocation of patients after implantation of the device, rather than before implantation, is an important source of bias, because these trials likely overestimate the potential benefits of the intervention.

\section{Statistical analysis}

Data were pooled using the random-effects model, and treatment effect was expressed as a relative risk. Heterogeneity was evaluated using the $I^{2}$ statistic. Subgroup analysis was conducted for New York Heart Association (NYHA) class. The optimum information size was considered for assessing the minimum amount of information required in the literature to reach reliable conclusions about cardiac resynchronization therapy. ${ }^{16-18}$

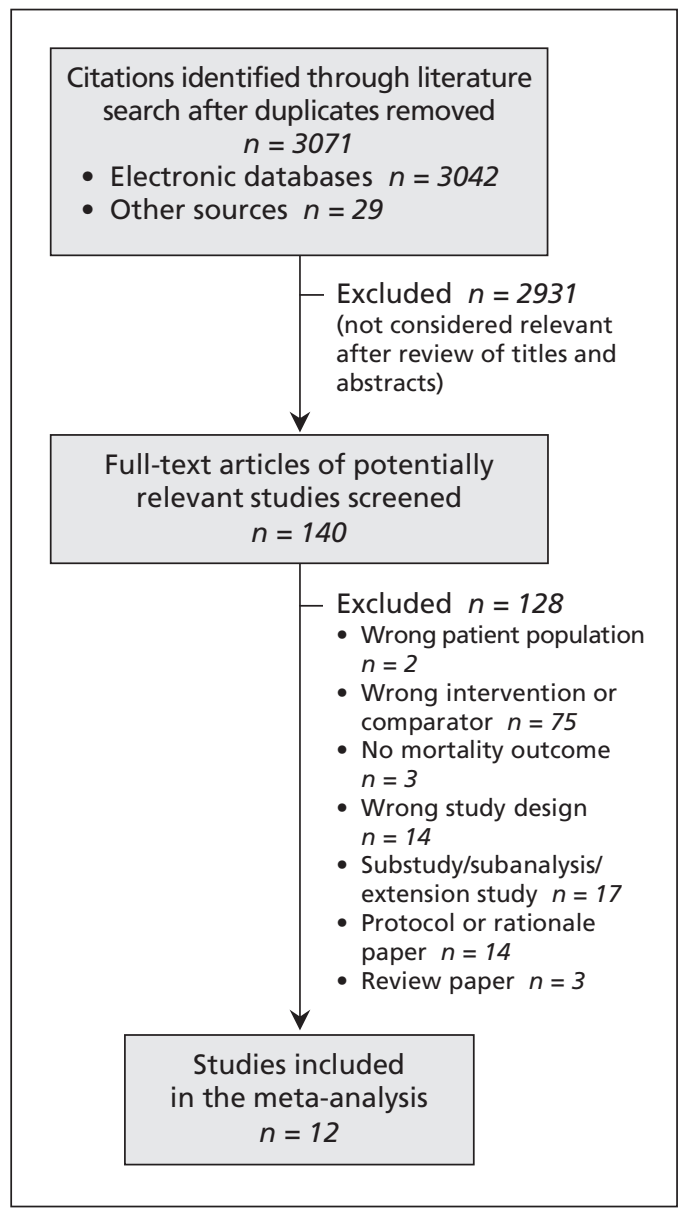

Figure 1: Flow diagram of selection of studies for the meta-analysis. 


\section{Results}

The literature search identified 3071 citations (Figure 1). Of these, the full-text versions of 140 articles were retrieved for further review. (The list of excluded studies is available in Appendix 3, at www.cmaj.ca/cgi/content/full /cmaj.101685/DC1.) If duplicate reports of the same study were found in preliminary abstracts and articles, the data from the most complete dataset were analyzed. In total, 12 trials met the selection criteria for inclusion in our metaanalysis. ${ }^{14,19-29}$

The characteristics of the 12 trials are summarized in Table 1 (additional details about the studies are available in Appendix 4, at www.cmaj.ca /cgi/content/full/cmaj.101685/DC1). A total of 7538 patients were enrolled in these trials (4244 in the cardiac resynchronization therapy groups and 3294 in the control groups). Five trials compared cardiac resynchronization therapy plus optimal therapy $(n=1342)$ with optimal medical therapy alone $(n=1013){ }^{20,21,24,26,27}$ Seven trials compared cardiac resynchronization therapy and an implantable defibrillator $(n=2902)$ with an implantable defibrillator $(n=2281))^{14,19,22,23,25,28,29}$ The length of follow-up ranged from 3 to 40 months. Five studies had a follow-up of 12 months or less. ${ }^{19-23}$ Male patients accounted for $63 \%$ to $89 \%$ of the study populations. The mean age varied from 62 to 66 years.

All of the 12 studies included patients with ischemic (38\%-70\% of patients) and nonischemic cardiomyopathy. The mean left ventricular ejection fraction was consistent across the studies $(21 \%-25 \%)$. The distribution by NYHA class was as follows: four studies enrolled only patients with NYHA class I or II heart failure; four other studies enrolled only patients with NYHA class III or IV disease; in the remaining four studies, $8 \%-80 \%$ of patients had NYHA class I or II disease (20\%-92\% had NYHA class III or IV disease). Although the minimum duration of QRS interval required for patient enrolment differed between the studies, the mean QRS interval was similar across the studies (153-176 ms).

The risk of bias was often low except for

Table 1: Characteristics of 12 studies included in the meta-analysis of cardiac resynchronization therapy for congestive heart failure

\begin{tabular}{|c|c|c|c|c|c|c|c|c|c|c|}
\hline Study & $\begin{array}{l}\text { No. of patients in } \\
\text { intervention/control } \\
\text { groups; }{ }^{*} \text { study design }\end{array}$ & $\begin{array}{l}\text { Mean } \\
\text { length of } \\
\text { follow-up, } \\
\text { mo }\end{array}$ & $\begin{array}{l}\text { Age, yr, } \\
\text { mean } \\
\text { (SD) }\end{array}$ & $\begin{array}{l}\text { Male, } \\
\%\end{array}$ & $\begin{array}{l}\text { Ischemic } \\
\text { cardio- } \\
\text { myopathy, } \\
\%\end{array}$ & $\begin{array}{l}\text { Mean } \\
\text { ejection } \\
\text { fraction, } \\
\% \text { (SD) }\end{array}$ & $\begin{array}{c}\text { QRS } \\
\text { interval, ms, } \\
\text { mean (SD) }\end{array}$ & $\begin{array}{l}\text { NYHA } \\
\text { class, \% }\end{array}$ & $A F, \%$ & RBBB, \% \\
\hline $\begin{array}{l}\text { Lozano et al., } \\
2000^{19}\end{array}$ & $\begin{array}{l}\text { CRT-ICD/ICD (109/113); } \\
\text { crossover }\end{array}$ & 3 & $65(10)$ & 83 & 68 & $22(0.007)$ & NR & $\begin{array}{l}\text { I/II: } 35 \\
\text { III/IV: } 65\end{array}$ & NR & NR \\
\hline $\begin{array}{l}\text { MUSTIC, } \\
2001^{20}\end{array}$ & $\begin{array}{l}\text { CRT/OMT (29/29); } \\
\text { crossover }\end{array}$ & 6 & $63(10)$ & 75 & NR & NR & $176(19)$ & I/II: 100 & NR & NR \\
\hline $\begin{array}{l}\text { MIRACLE ICD, } \\
2003^{22}\end{array}$ & $\begin{array}{l}\text { CRT-ICD/ICD (187/182); } \\
\text { parallel }\end{array}$ & 6 & $67(10)$ & 77 & 70 & $24(6.2)$ & $163(22)$ & III/IV: 100 & 0 & 13 \\
\hline $\begin{array}{l}\text { MIRACLE } \\
\text { ICD II, 2004 }\end{array}$ & $\begin{array}{l}\text { CRT-ICD/ICD (85/101); } \\
\text { parallel }\end{array}$ & 6 & $63(12)$ & 89 & 57 & $24.5(6.7)$ & 165 (24) & I/II: 100 & NR & 16 \\
\hline $\begin{array}{l}\text { COMPANION } \\
2004^{24}\end{array}$ & $\begin{array}{l}\text { CRT-ICD/CRT/OMT } \\
\text { (595/617/308); } \\
\text { parallel }\end{array}$ & $14.8-16.5$ & 67 & 67 & 55 & 22 & 160 & III/IV: 100 & NR & 10 \\
\hline $\begin{array}{l}\text { CARE-HF, } \\
2005^{26}\end{array}$ & $\begin{array}{l}\text { CRT/OMT (409/404); } \\
\text { parallel }\end{array}$ & 29.4 & 66 & 74 & 38 & 25 & 160 & III/IV: 100 & 0 & NR \\
\hline $\begin{array}{l}\text { VECTOR, } \\
2005^{27}\end{array}$ & $\begin{array}{l}\text { CRT/OMT (59/47); } \\
\text { parallel }\end{array}$ & 19.9 & $67.1(9.7)$ & 63 & NR & NR & $N R$ & $\begin{array}{l}\text { I/II: } 29 \\
\text { III/IV: } 71\end{array}$ & NR & $N R$ \\
\hline $\begin{array}{l}\text { REVERSE, } \\
2008^{28}\end{array}$ & $\begin{array}{l}\text { CRT-ICD/ICD (419/191); } \\
\text { parallel }\end{array}$ & 12 & $62(11)$ & 79 & 55 & $27(7)$ & $153(12)$ & I/II: 100 & 0 & NR \\
\hline $\begin{array}{l}\text { MADIT-CRT, } \\
2009^{29}\end{array}$ & $\begin{array}{l}\text { CRT-ICD/ICD (1089/731); } \\
\text { parallel }\end{array}$ & 28.8 & 65 (11) & 75 & 55 & $24(5)$ & $65 \%>150$ & I/II: 100 & 12 & 13 \\
\hline RAFT, $2010^{14}$ & $\begin{array}{l}\text { CRT-ICD/ICD (894/904); } \\
\text { parallel }\end{array}$ & 40 & $66 \quad(9)$ & 83 & 67 & $23(5)$ & $158(24)$ & $\begin{array}{l}\text { I/II: } 80 \\
\text { III/IV: } 20\end{array}$ & 13 & 9 \\
\hline
\end{tabular}


implantation of the cardiac synchronization therapy device after randomization ${ }^{19-23,25,27,28}$ (Table 2). (For details see Appendix 5, at www.cmaj.ca/cgi /content/full/cmaj.101685/DC1).

\section{Overall effect of cardiac resynchronization therapy}

A summary of the overall effect of cardiac resynchronization therapy on mortality is provided in Figure 2. In general, a relative risk reduction of $22 \%$ in mortality was found when cardiac resynchronization therapy was added to treatment (relative risk [RR] 0.78, 95\% confidence interval [CI] 0.70-0.87); there was no significant heterogeneity across the trials $\left(I^{2}=0\right)$.

\section{Cardiac resynchronization therapy versus optimal medical therapy alone}

Five studies evaluated the effect on mortality of cardiac resynchronization therapy plus optimal medical therapy versus optimal medical therapy alone..$^{20,21,24,26,27}$ All of these studies involved patients with NYHA class III or IV heart failure. A significant relative risk reduction of $27 \%$ in mortality was found (RR 0.73 , 95\% CI $0.62-0.85$ ) (Figure 2). There was no significant heterogeneity across the studies $\left(I^{2}=0\right)$; all studies indicated a relative risk reduction in mortality, but only the largest study (CARE-HF [Cardiac Resynchronization in Heart Failure]) reported a significant reduction (RR 0.65, 95\% CI 0.53 $0.80){ }^{26}$ Without the CARE-HF study, the reduction in mortality in the treatment group was not significant compared with optimal medical therapy alone. The CARE-HF study and the COMPANION (Comparison of Medical Therapy, Pacing, and Defibrillation in Heart Failure) study, ${ }^{24}$ were the principal studies that led to the change in guidelines recommending that cardiac resynchronization therapy be used in addition to optimal medical therapy in patients with NYHA class III heart failure and ambulatory patients with NYHA class IV disease.

\section{Cardiac resynchronization therapy and implantable defibrillator versus implantable defibrillator}

The intervention of cardiac resynchronization therapy and an implantable defibrillator, in addition to optimal medical therapy, was considered in seven studies that reported mortality. ${ }^{14,19,22,23,25,28,29}$ Patients with a spectrum of heart failure ranging from NYHA class I to IV were enrolled in these studies. A significant relative risk reduction of $17 \%$ was found (RR 0.83 , 95\% CI 0.72-0.96) (Figure 2). Although there was no significant heterogeneity across the studies $\left(I^{2}=0\right)$, before the RAFT study, three studies indicated a relative risk reduction in mortality and three studies indicated a relative risk increase; none of these relative risks was significant. RAFT was the largest study, with a significant relative risk reduction of $20 \%$ (RR $0.80,95 \%$ CI $0.67-0.94) .{ }^{14}$ Without the RAFT study, the reduction in mortality with the intervention of cardiac resynchronization therapy and an implantable defibrillator was not significant (RR $0.93,95 \%$ CI 0.70-1.23).

\begin{tabular}{|c|c|c|c|c|c|c|c|c|}
\hline Study & $\begin{array}{l}\text { Adequate } \\
\text { sequence } \\
\text { generation }\end{array}$ & $\begin{array}{l}\text { Concealment } \\
\text { of allocation }\end{array}$ & $\begin{array}{l}\text { Single or } \\
\text { double } \\
\text { blinding }\end{array}$ & $\begin{array}{l}\text { Blinding to } \\
\text { outcome* }\end{array}$ & $\begin{array}{l}\text { Incomplete } \\
\text { outcome } \\
\text { data } \\
\text { addressed }\end{array}$ & $\begin{array}{l}\text { Free of } \\
\text { selective } \\
\text { reporting }\end{array}$ & $\begin{array}{l}\text { Free of } \\
\text { other bias }\end{array}$ & $\begin{array}{c}\text { Implantation } \\
\text { after } \\
\text { randomization }\end{array}$ \\
\hline Loranzo et al. ${ }^{19}$ & ND & ND & ND & Yes & Yes & Yes & Yes & No \\
\hline MUSTIC ${ }^{20}$ & Yes & ND & Yes & Yes & Yes & Yes & Yes & No \\
\hline MIRACLE $^{21}$ & Yes & Yes & Yes & Yes & Yes & Yes & Yes & No \\
\hline MIRACLE ICD ${ }^{22}$ & Yes & Yes & Yes & Yes & Yes & Yes & Yes & No \\
\hline MIRACLE ICD $\|^{23}$ & Yes & Yes & Yes & Yes & Yes & Yes & Yes & No \\
\hline COMPANION $^{24}$ & ND & ND & Yes & Yes & Yes & Yes & Yes & Yes \\
\hline RHYTHM ICD ${ }^{25}$ & ND & ND & Yes & Yes & ND & Yes & Yes & No \\
\hline CARE-HF ${ }^{26}$ & Yes & Yes & Yes & Yes & Yes & Yes & Yes & Yes \\
\hline VECTOR $^{27}$ & ND & ND & Yes & Yes & ND & Yes & Yes & No \\
\hline REVERSE $^{28}$ & ND & ND & Yes & Yes & Yes & Yes & Yes & No \\
\hline MADIT-CRT ${ }^{29}$ & ND & ND & Yes & Yes & Yes & Yes & Yes & Yes \\
\hline $\mathrm{RAFT}^{14}$ & Yes & Yes & Yes & Yes & Yes & Yes & Yes & Yes \\
\hline
\end{tabular}


Patients with NYHA class I or II disease

The intervention of cardiac resynchronization therapy and an implantable defibrillator versus an implantable defibrillator in patients with NYHA class I or II heart failure was considered in four studies that reported mortality. A significant relative risk reduction of $20 \%$ in mortality was found (RR 0.80, 95\% CI 0.67-0.96) ${ }^{14,23,28,29}$ (Figure 3). There was no significant heterogeneity across the studies $\left(I^{2}=0\right)$, with three studies having a nonsignificant reduction or increase in relative risk $^{23,28,29}$ and only the RAFT study having a significant relative risk reduction of $26 \%$ (RR 0.74 , 95\% CI 0.59-0.92). ${ }^{14}$ Without the RAFT study, the reduction in mortality with cardiac resynchronization therapy and an implantable defibrillator was not significant (RR 0.97, 95\% CI 0.70-1.34). The MADIT-CRT (Multicenter Automatic De- fibrillator Implantation Trial - Cardiac Resynchronization Therapy) study was larger, but it reported a nonsignificant relative risk reduction of only $6 \%$ (RR $0.94,95 \%$ CI $0.67-1.32$ ). ${ }^{29}$

\section{Patients with NYHA class III or IV disease}

Four studies considered the effect on mortality among patients with NYHA class III or IV heart failure when cardiac resynchronization therapy was combined with an implantable defibrillator. ${ }^{14,19,22,25}$ A nonsignificant relative risk reduction of $14 \%$ was found (RR $0.86,95 \%$ CI $0.69-1.07$ ) (Figure 3); there was no significant heterogeneity across the studies $\left(I^{2}=0\right)$. Without the inclusion of the RAFT study, the other three studies combined had a relative risk reduction of $17 \%$ (RR 0.83 , 95\% CI 0.48-1.43) with a wide confidence interval.

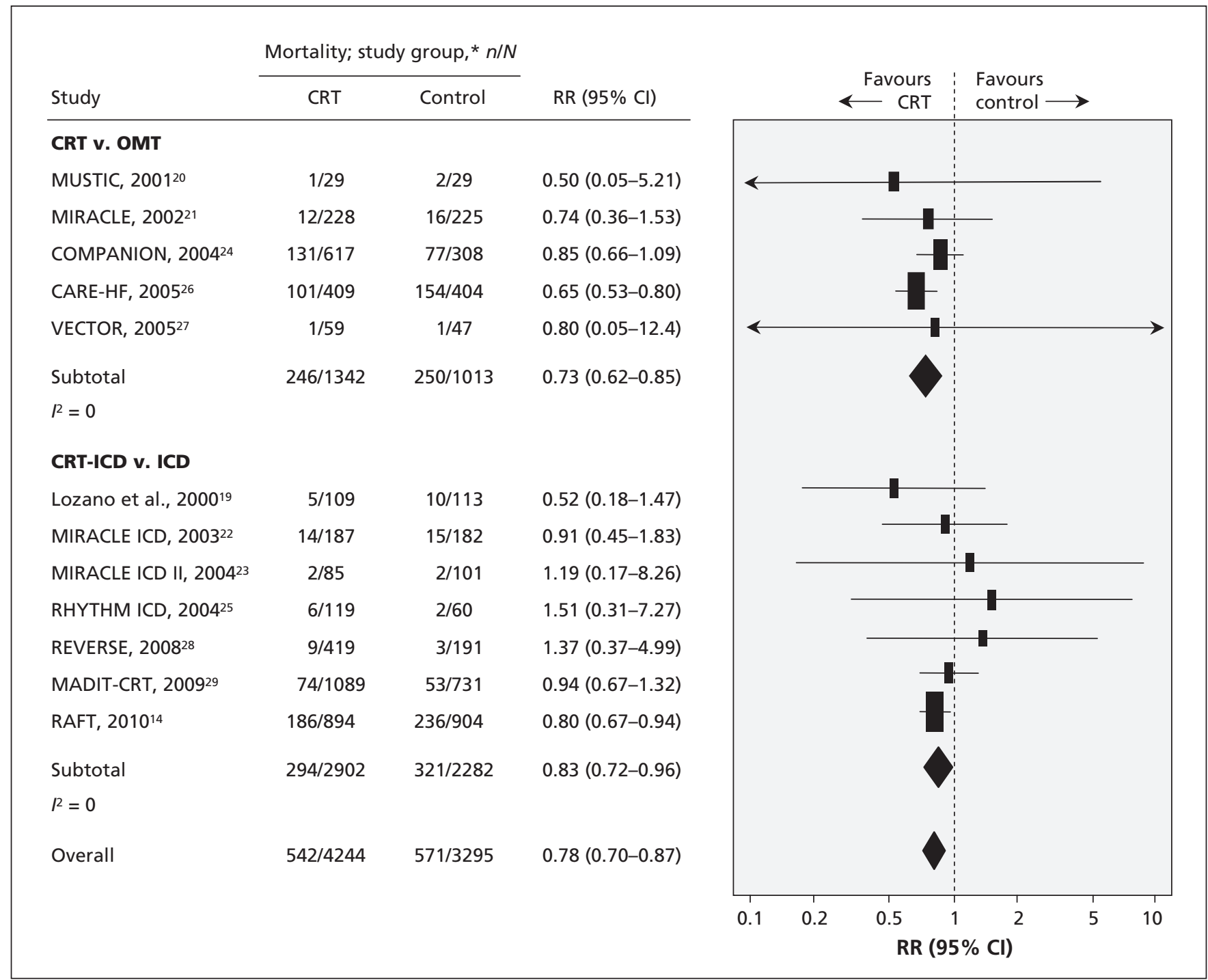

Figure 2: Results of random-effects meta-analysis of overall mortality among patients with heart failure given cardiac resynchronization therapy (CRT) in addition to optimal medical therapy (OMT) or implantable cardioverter defibrillator (ICD). Values less than 1.0 indicate a decreased risk of death with cardiac resynchronization therapy. Note $\mathrm{Cl}=$ confidence interval, $\mathrm{RR}=$ relative risk. For complete study names, see Box 1. *All patients received optimal medical therapy. 


\section{Optimal information size}

With the recent addition of the RAFT study to the body of evidence on cardiac resynchronization therapy in patients with mildly symptomatic or advanced heart failure, the Lan-DeMets se quential monitoring boundary ${ }^{17}$ has now been crossed (Figure 4). The cumulative evidence is now conclusive that the addition of cardiac resynchronization therapy to optimal medical therapy or to implantable defibrillator significantly reduces mortality (for details see Appendix 6, available at www.cmaj.ca/cgi/content/full/cmaj $.101685 / \mathrm{DC} 1)$.

\section{Interpretation}

Our findings indicate an unequivocal benefit of cardiac resynchronization therapy in addition to optimal medical therapy or an implantable cardioverter defibrillator in reducing all-cause mortality. This effect was particularly evident among patients with NYHA class II heart failure, a group in which a significant reduction in mortality had not been shown before the RAFT study, even in the presence of an implantable defibrillator.

The overall beneficial incremental effect of cardiac resynchronization therapy is supported by findings from the analysis of optimal information size. With the recently reported RAFT study, the sequential monitoring boundary has now been crossed, which indicates that the cumulative evidence now conclusively shows that the addition of cardiac resynchronization therapy to optimal medical therapy or to implantable defibrillator significantly reduces mortality among patients with mildly symptomatic or advanced heart failure. This sequential monitoring boundary is designed to be restrictive so that, when crossed, there is clear evidence of benefit. The cumulative evidence available from the previous 11 studies was not sufficient for the boundary to be crossed.

Our findings add to those of prior metaanalyses examining the effects of cardiac resynchronization therapy among patients with heart failure. ${ }^{13,30-32}$ Previous meta-analyses showed observations similar to ours when comparing

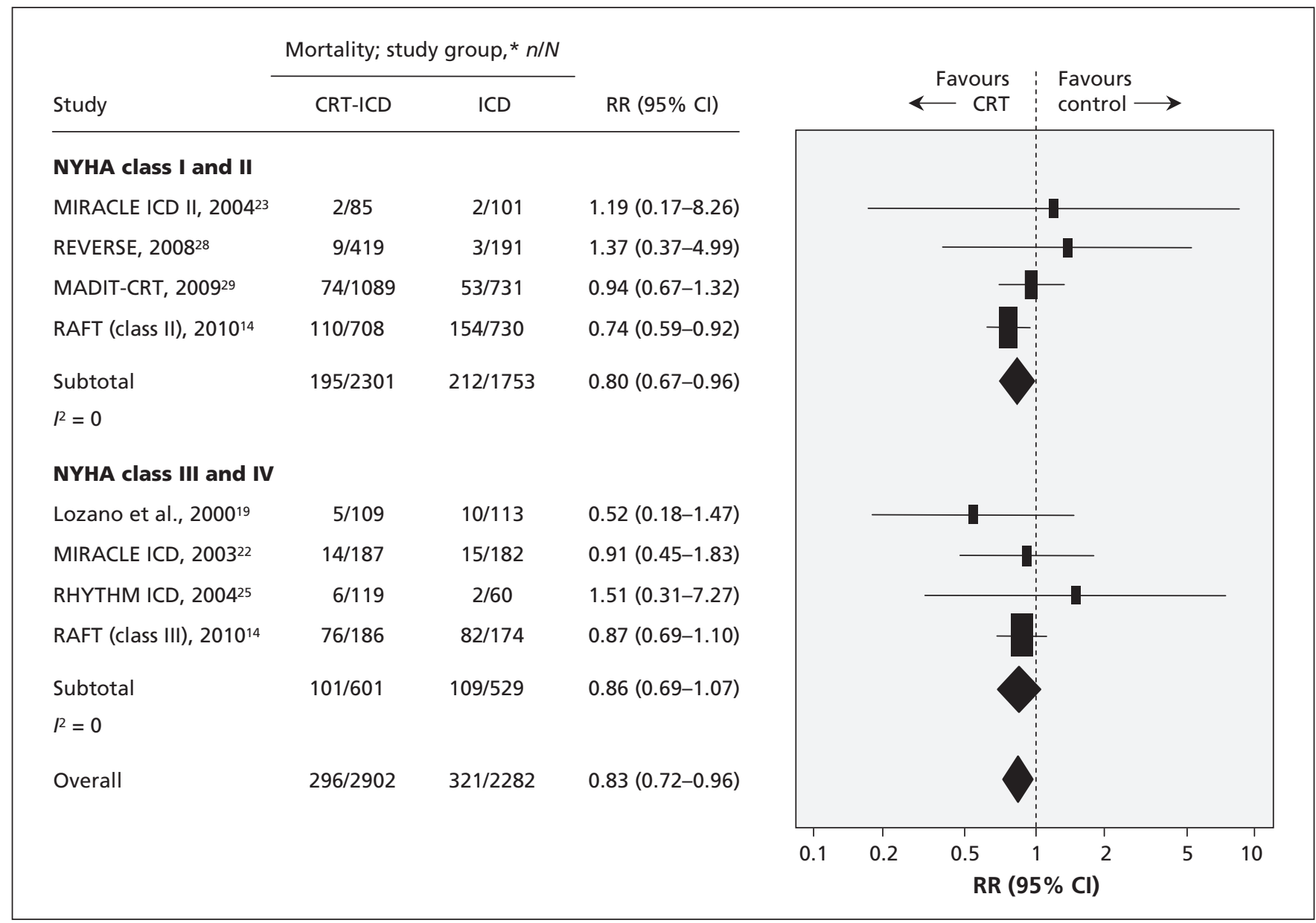

Figure 3: Results of random-effects meta-analysis of overall mortality among patients with heart failure given cardiac resynchronization therapy plus an implantable cardioverter defibrillator (CRT-ICD) versus an implantable defibrillator (ICD), by New York Heart Association (NYHA) class. Values less than 1.0 indicate a decreased risk of death with cardiac resynchronization therapy. Note $\mathrm{Cl}=$ confidence interval, $\mathbf{R R}=$ relative risk. For complete study names, see Box 1. *All patients received optimal medical therapy. 
cardiac resynchronization therapy with optimal medical therapy alone, ${ }^{13,32}$ but they did not show a mortality benefit when comparing cardiac resynchronization therapy plus an implantable defibrillator with an implantable defibrillator. The addition of the data from the RAFT study in our review substantially changed these findings, supporting cardiac resynchronization therapy over and above an implantable defibrillator in eligible patients with heart failure.

The lack of a significant relative risk reduction in mortality among patients with NYHA class III heart failure may be explained by several factors. Many studies had short follow-up, with a range of 3-12 months. ${ }^{19-23}$ In addition, the number of patients with NYHA class III disease $(n=1330)$ was significantly smaller than the group with NYHA class II disease $(n=3947)$. This difference is predominantly due to the publication of the CARE-HF study, which showed a significant reduction in mortality with cardiac resynchronization therapy over optimal medical therapy alone. That study's findings resulted in the American College of Cardiology/American Heart Association Task Force on Practice Guidelines to issue a class I recommendation in 2008 for cardiac resynchronization therapy in patients with NYHA class III heart failure, a left ventricular ejection fraction of less than $35 \%$ and a QRS interval of more than $130 \mathrm{~ms} .^{33}$ The RAFT study, which originally enrolled patients with either
NYHA class II or III heart failure, changed its inclusion criteria in 2006 to include only those with NYHA class II disease, thereby limiting the number of patients with NYHA class III disease available for analysis. No further studies have been done involving patients with NYHA class III heart failure to examine the effect of cardiac resynchronization therapy over a standard implantable defibrillator.

\section{Limitations}

There are some limitations to our meta-analysis that are inherent to the studies we included. First, the timing of randomization to cardiac resynchronization therapy was not uniform across the studies. In many studies, randomization was done after a successful implantation, instead of at study entry. Deaths that may have occurred before or during implantation were not counted in these instances.

Second, optimization of medical therapy was not accurately specified at baseline in the studies. This issue is of importance when examining the data by NYHA class.

Third, many studies did not report outcomes by NYHA class; therefore, the data used in the NYHA II and III classification may not be completely accurate, because the raw data by NYHA class were not uniformly available.

Fourth, follow-up varied greatly, with a large number of studies not reporting follow-up beyond 6 months.

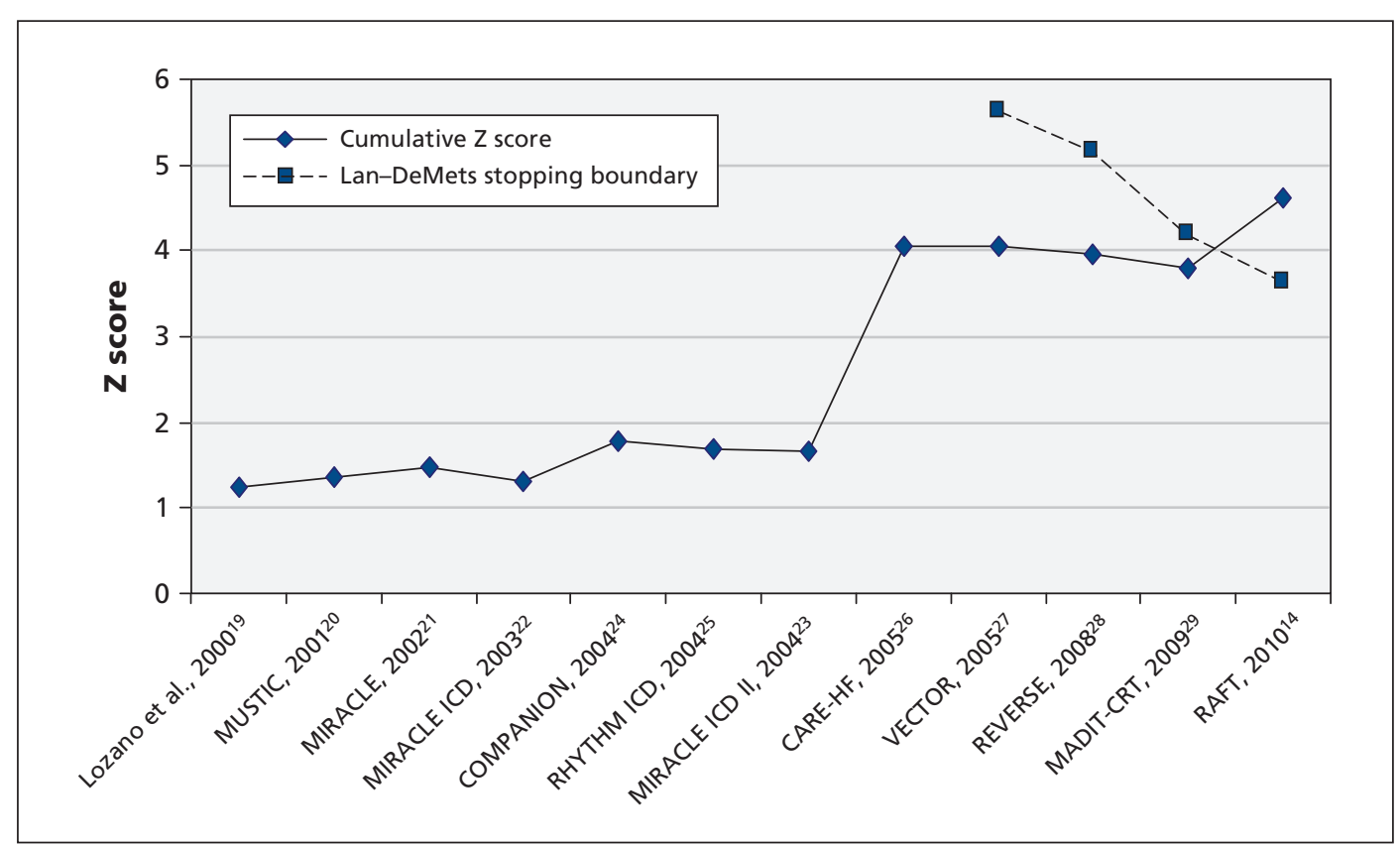

Figure 4: Cumulative meta-analysis of the effect on overall mortality of cardiac resynchronization therapy in addition to optimal medical therapy or implantable defibrillator therapy among patients with mildly symptomatic or advanced heart failure. With the addition of the RAFT study, the cumulative $Z$ score crosses the Lan-DeMets sequential monitoring boundary, ${ }^{17}$ which indicates that the cumulative evidence supporting cardiac resynchronization therapy in addition to optimal medical therapy or defibrillator therapy is now conclusive. For complete study names, see Box 1. 


\section{Box 1: Full names of trials included in the meta-analysis}

- CARE-HF = Cardiac Resynchronization in Heart Failure Trial

- COMPANION = Comparison of Medical Therapy, Pacing, and Defibrillation in Heart Failure

- MADIT-CRT = Multicenter Automatic Defibrillator Implantation Trial with Cardiac Resynchronization Therapy

- MIRACLE = Multicenter Insync Randomized Clinical Evaluation

- MUSTIC = Multisite Stimulation in Cardiomyopathies Study

- RAFT = Resynchronization/Defibrillation for Ambulatory Heart Failure Trial

- REVERSE = Resynchronization Reverses Remodeling in Systolic Left Ventricular Dysfunction

- RHYTHM = Resynchronization for Hemodynamic Treatment for Heart Failure Management

- $\operatorname{VECTOR}=$ Ventricular Resynchronization Therapy Randomized Trial
These limitations may significantly underestimate the true effect of cardiac resynchronization therapy among patients with heart failure, particularly when results of studies with prolonged follow-up are compared with those of shorter duration. Finally, the mechanism by which cardiac resynchronization therapy prevents mortality in this patient population remains to be elucidated.

\section{Conclusion}

Our meta-analysis showed a significant reduction in mortality with cardiac resynchronization therapy in addition to either optimal medical therapy or an implantable cardioverter defibrillator. Although this benefit was evident across the spectrum of symptomatic heart failure, it was particularly evident among patients with mildly symptomatic heart failure (NYHA class II disease) who had a QRS interval of more than $120 \mathrm{~ms}$, a finding not previously shown, even in the presence of an implantable defibrillator. The added risk of performing cardiac resynchronization in this patient population must be weighed against the benefit. Cardiac resynchronization therapy may now be extended to a much wider proportion of patients with heart failure, improving long-term outcomes in this growing population.

\section{References}

1. Ross H, Howlett J, Arnold JM, et al. Treating the right patient at the right time: access to heart failure care. Can J Cardiol 2006; 22:749-54.

2. Johansen H, Strauss B, Arnold JM, et al. On the rise: The current and projected future burden of congestive heart failure hospitalization in Canada. Can J Cardiol 2003;19:430-5.

3. Pfeffer MA, Braunwald E, Moye LA, et al. Effect of captopril on mortality and morbidity in patients with left ventricular dysfunction after myocardial infarction. Results of the survival and ventricular enlargement trial. The SAVE Investigators. $N$ Engl J Med 1992;327:669-77.

4. Effect of enalapril on mortality and the development of heart failure in asymptomatic patients with reduced left ventricular ejection fractions. The SOLVD Investigators. $N$ Engl J Med 1992:327:685-91.

5. The Cardiac Insufficiency Bisoprolol Study II (CIBIS-II). a randomised trial. Lancet 1999;353:9-13.
6. Hjalmarson A, Goldstein S, Fagerberg B, et al. Effects of controlled-release metoprolol on total mortality, hospitalizations, and well-being in patients with heart failure: the Metoprolol CR/XL Randomized Intervention Trial in congestive heart failure (MERIT-HF). MERIT-HF Study Group. JAMA 2000;283: 1295-302.

7. Pitt B, Zannad F, Remme WJ, et al. The effect of spironolactone on morbidity and mortality in patients with severe heart failure. Randomized Aldactone Evaluation Study Investigators. N Engl J Med 1999;341:709-17.

8. Bardy GH, Lee KL, Mark DB, et al. Amiodarone or an implantable cardioverter-defibrillator for congestive heart failure. N Engl J Med 2005;352:225-37.

9. Woo GW, Petersen-Stejskal S, Johnson JW, et al. Ventricular reverse remodeling and 6-month outcomes in patients receiving cardiac resynchronization therapy: analysis of the MIRACLE study. J Interv Card Electrophysiol 2005;12:107-13.

10. St John Sutton M, Ghio S, Plappert T, et al. Cardiac resynchronization induces major structural and functional reverse remodeling in patients with New York Heart Association class I/II heart failure. Circulation 2009;120:1858-65.

11. St John Sutton MG, Plappert T, Abraham WT, et al. Effect of cardiac resynchronization therapy on left ventricular size and function in chronic heart failure. Circulation 2003;107:1985-90.

12. Solomon SD, Foster E, Bourgoun M, et al. Effect of cardiac resynchronization therapy on reverse remodeling and relation to outcome: Multicenter Automatic Defibrillator Implantation Trial: Cardiac Resynchronization Therapy. Circulation 2010; 122:985-92.

13. McAlister FA, Ezekowitz J, Hooton N, et al. Cardiac resynchronization therapy for patients with left ventricular systolic dysfunction: a systematic review. JAMA 2007;297:2502-14.

14. Tang AS, Wells GA, Talajic M, et al.; ResynchronizationDefibrillation for Ambulatory Heart Failure Trial (RAFT) Investigators. Cardiac-resynchronization therapy for mild-to-moderate heart failure. N Engl J Med 2010;363:2385-95.

15. Altman DG, Antes G, Gotzsche P, et al. Assessing risk of bias in inlcuded studies. In: Higgins JPT, Altman DG, editors. Cochrane handbook for systematic reviews of interventions. Version 5.0.0 (updated February 2008). London (UK): The Cochrane Collaboration; 2008. Available: www.cochrane-handbook.org (accessed 2011 Jan. 12).

16. Pogue JM, Yusuf S. Cumulating evidence from randomized trials: utilizing sequential monitoring boundaries for cumulative meta-analysis. Control Clin Trials 1997;18:580-93.

17. Lan KKG, DeMets DL. Discrete sequential boundaries for clinical trials. Biometrika 1983;70:659-63.

18. Fleming TR, Harrington DP, O'Brien PC. Designs for group sequential tests. Control Clin Trials 1984;5:348-61.

19. Lozano I, Bocchiardo M, Achtelik M, et al. Impact of biventricular pacing on mortality in a randomized crossover study of patients with heart failure and ventricular arrhythmias. Pacing Clin Electrophysiol 2000;23:1711-2.

20. Cazeau S, Leclercq C, Lavergne T, et al.; Multisite Stimulation in Cardiomyopathies (MUSTIC) Study Investigators. Effects of multisite biventricular pacing in patients with heart failure and intraventricular conduction delay. N Engl J Med 2001;344:873-80.

21. Abraham WT, Fisher WG, Smith AL, et al.; Multicenter Insync Randomized Clinical Evaluation (MIRACLE) Study Group. Cardiac resynchronization in chronic heart failure. $N$ Engl J Med 2002;346:1845-53.

22. Young JB, Abraham WT, Smith AL, et al. Combined cardiac resynchronization and implantable cardioversion defibrillation in advanced chronic heart failure: the MIRACLE ICD Trial. JAMA 2003;289:2685-94.

23. Abraham WT, Young JB, Leon AR, et al. Effects of cardiac resynchronization on disease progression in patients with left ventricular systolic dysfunction, an indication for an implantable cardioverter-defibrillator, and mildly symptomatic chronic heart failure. Circulation 2004;110:2864-8.

24. Bristow MR, Saxon LA, Boehmer J, et al. Cardiac-resynchronization therapy with or without an implantable defibrillator in advanced chronic heart failure. N Engl J Med 2004;350:2140-50.

25. St. Jude Medical ${ }^{\varpi}$ Epic $^{T M} H F$ System including the Epic ${ }^{T M} H F$ model $V$-338 cardiac resynchronization therapy defibrillator, the Aescula ${ }^{T M}$ LV model $1055 \mathrm{~K}$ lead, the QuickSite ${ }^{T M}$ LV model $1056 \mathrm{~K}$ lead, and the model 3307, v4.5m programmer software: summary of safety and effectiveness. Silver Springs (MD): US Food and Drug Administration; 2004. Available: www.accessdata.fda.gov /scripts/cdrh/cfdocs/cfTopic/pma/pma.cfm?num=p030054 (accessed 2011 Jan. 12).

26. Cleland JG, Daubert JC, Erdmann E, et al. The effect of cardiac resynchronization on morbidity and mortality in heart failure. N Engl J Med 2005;352:1539-49. 
27. St. Jude Medical Frontier ${ }^{T M}$ model $5508 L$ and Frontier ${ }^{T M}$ II model 5586 cardiac resynchronization therapy pacemakers (CRT-P) supported on the model 3510 programmer platforms with the model 3307, v4.8m programmer software: summary of safety and effectiveness. Silver Spring (MD): US Food and Drug Administration; 2005. Available: www.accessdata.fda.gov/scripts/cdrh /cfdocs/cfTopic/pma/pma.cfm?num=p030035s003 (accessed 2011 Jan. 12).

28. Linde C, Abraham WT, Gold MR, et al. Randomized trial of cardiac resynchronization in mildly symptomatic heart failure patients and in asymptomatic patients with left ventricular dysfunction and previous heart failure symptoms. J Am Coll Cardiol 2008;52:1834-43.

29. Moss AJ, Hall WJ, Cannom DS, et al. Cardiac-resynchronization therapy for the prevention of heart-failure events. $N$ Engl J Med 2009;361:1329-38.

30. McAlister FA, Ezekowitz JA, Wiebe N, et al. Systematic review: cardiac resynchronization in patients with symptomatic heart failure. Ann Intern Med 2004;141:381-90.

31. Lubitz SA, Leong-Sit P, Fine N, et al. Effectiveness of cardiac resynchronization therapy in mild congestive heart failure: systematic review and meta-analysis of randomized trials. Eur $J$ Heart Fail 2010;12:360-6.

32. Bradley DJ, Bradley EA, Baughman KL, et al. Cardiac resynchronization and death from progressive heart failure: a metaanalysis of randomized controlled trials. JAMA 2003;289:730-40.

33. Epstein AE, Dimarco JP, Ellenbogen KA, et al. ACC/AHA/HRS 2008 guidelines for device-based therapy of cardiac rhythm abnormalities: executive summary. Heart Rhythm 2008;5:934-55.

Competing interests: George Wells, Jeffrey Healey, Mario Talajic, Malcolm Arnold and Anthony Tang were also authors of the RAFT study. Ratika Parkash has received a research grant from Medtronic Canada for research into outcomes with implantable defibrillators. George Wells has received speaker fees from Medtronic Canada. Jeffrey Healey has received research grants from St. Jude Medical and Boston Scientific for research into the role of defibrillation testing at the time of implantation and the significance of pacemaker-detected atrial tachyarrhythmias; he has received consulting fees from St. Jude Medical. Mario Talajic has served on an advisory board for Medtronic and has received speaker fees from Medtronic. Malcolm Arnold has served on ad hoc advisory boards for Medtronic and Biotronic and has received speaker fees from Medtronic for CME talks about device therapies. No competing interests declared by Shannon Sullivan, Joan Peterson, Elizabeth Yetisir, Patricia Theoret-Patrick or Marilynn Luce.

Affiliations: From the University of Ottawa Heart Institute (Wells, Sullivan, Peterson, Yetisir, Theoret-Patrick, Luce, Tang), Ottawa, Ont.; the QEII Health Sciences Centre (Parkash), Halifax, NS; the Population Health Research Institute (Healey), Hamilton, Ont.; the Montréal Heart Institute (Talajic), Montréal, Que.; University Hospital (Arnold), London, Ont.; and the Island Medical Program (Tang), University of British Columbia, Victoria, BC

Contributors: George Wells, Ratika Parkash, Jeffrey Healey, Mario Talajic, Malcolm Arnold and Anthony Tang participated in the development of the study concept. George Wells, Ratika Parkash, Jeffrey Healey, Shannon Sullivan, Joan Peterson, Elizabeth Yetisir and Anthony Tang contributed to the collection, analysis and interpretation of the data. Mario Talajic, Malcolm Arnold, Patricia Theoret-Patrick and Marilynn Luce participated in data collection and interpretation of the data. George Wells, Ratika Parkash, Jeffrey Healey, Shannon Sullivan, Joan Peterson, Elizabeth Yetisir and Anthony Tang participated in the drafting of the manuscript. All of the authors revised the manuscript for important intellectual content and approved the final version submitted for publication.

Funding: This paper was supported by funding from the Canadian Institutes of Health Research as a University/Industry grant, with Medtronic Canada as the industrial partner.

\section{S SECUREGARD Single-use, Retractable Safety} Syringes are now available in Canada!

With "Re-use Prevention Features" as required by the World Health Organization and UNICEF!

A cost-effective solution to meet injection safety requirements. Available in 1,3 and $5 \mathrm{~mL}$ sizes.

CALL NOW FOR PRICING AND AVAILABILITY

$$
1-800-998-8251
$$

For a complete list of configurations and availability, please visit our website at WWW.responsescientific.ca
Response Scientific Canada Inc. 107-50 Ottawa Street South Kitchener, Ontario N2G 3S7 